Revista Brasileira de

Engenharia Agrícola e Ambiental

v. 12, n.5, p.486-492, 2008

Campina Grande, PB, UAEAg/UFCG - http://www.agriambi.com.br

agriambi

Protocolo 027.06 - 07/03/2006 • Aprovado em 31/01/2008

\title{
Variação vertical da temperatura do ar no dossel de plantas de batata
}

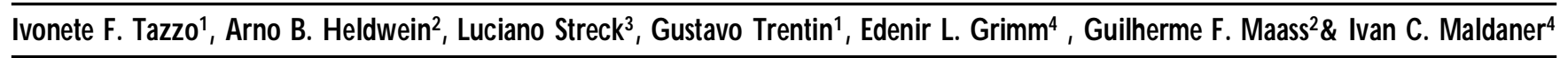

\section{RESU MO}

A temperatura do ar é um dos elementos meteorológicos mais importantes no condicionamento da infecção causada por patógenos, ante o que se propôs, com este trabalho, determinar a variação vertical da temperatura do ar no dossel de plantas de batata, cultivar Macaca; para tal, dois experimentos foram realizados, um na primavera, de 15/10 a 05/12/2003, em uma propriedade rural no município de Silveira Martins, RS, e o segundo no outono, de 27/03 a 08/06/2004, no Departamento de Fitotecnia da Universidade Federal de Santa M aria, RS. Foram instaladas uma torre com cinco níveis de medições psicrométricas cont́nuas e três repetições de psicrômetros, a meia altura das plantas e a 1,0 $\mathrm{m}$ de altura. Cada par psicrométrico constou de dois termômetros de resistência elétrica de platina (PT - 100), acomodados no interior de um mini-abrigo. Todos os sensores foram ligadosa uma datalogger. As diferenças médias de temperatura entre 2,2 e 0,15 $\mathrm{m}$ de altura $\left(T_{2,2}-T_{0,15}\right)$ em 2003, foram de $-1,72{ }^{\circ} \mathrm{C}$ no período diurno (das 11 às $17 \mathrm{~h}$ ) e de $+0,82^{\circ} \mathrm{C}$ no período noturno (das 21 às $4 \mathrm{~h}$ ). Em 2004 as diferenças médias de temperatura entre os níveis extremos de 2,0 e $0,10 \mathrm{~m}\left(\mathrm{~T}_{2,0}-\mathrm{T}_{0,10}\right)$ foram de $-1,12{ }^{\circ} \mathrm{C}$ no período diurno e de $-0,62{ }^{\circ} \mathrm{C}$ no período noturno. A temperatura média diuna é maior nos níveis inferiores do dossel, sendo os gradientes de temperatura do ar mais acentuados durante o período diurno do que durante a noite.

Palavras-chave: Solanum tuberosum, temperatura média, perfis térmicos

\section{Vertical variation of the air temperature in the potato canopy}

\begin{abstract}
Air temperature is one of the most important meteorological elements in the conditioning of infection caused by pathogens. The objective of this study was to determine the variation of air temperature in the canopy of potato plants, cv. Macaca. Two experiments were carried out, one in the spring in a rural farm in the county of Silveira Martins, RS, from 0 ctober 15 to December 5, 2003, and the second in the autumn in the experimental area of the Crop Production Department of Universidade Federal de Santa M aria, RS, from M arch 27 to June 8, 2004. A tower with five levels of continuous psicrometric measurements and three psicrometer repetitions was installed at the half height of the plants and at $1.0 \mathrm{~m}$ height. Each psicrometric couple consisted of two platinum resistance thermometers (PT - 100), installed inside mini-shelters. The sensors were plugged into a datalogger, the means at 10 min intervals being continually stored. The mean differences of temperature $\left(T_{2.2}-T_{0.15}\right)$ in the experimental period in the spring of 2003 were $-1.72{ }^{\circ} \mathrm{C}$ during the day $\left(11: 00\right.$ to $\left.17: 00 \mathrm{o}^{\prime} \mathrm{Clock}\right)$ and $+0.82{ }^{\circ} \mathrm{C}$ during the night (21:00 to 4:00 o'clock). In 2004 the mean differences of temperature $\left(T_{2.0}-T_{0.10}\right)$ were $-1.12{ }^{\circ} \mathrm{C}$ during the day and $-0.62{ }^{\circ} \mathrm{C}$ during the night. The mean temperature of the day was larger in the inferior levels of the canopy, being the gradients of air temperature more accentuated during the day period than in the night.
\end{abstract}

Key words: Solanum tuberosum, mean temperature, thermal profiles

\footnotetext{
${ }^{1}$ Doutoranda em Agronomia/UFSM. Av. Roraima, n.1000, prédio 77, CEP 97105-900 Santa Maria, RS. Fone: (55)3220-8179 ramal 235. E-mail: ivonetetazzo@yahoo.com.br, gustavotrentin@yahoo.com.br

2 Departamento de Fitotecnia/UFSM. Fone: (55)3220-8179 ramal 235. E-mail: heldwein@ccr.ufsm.br, maass. guilherme@universia.com.br

3 Pólo São Luís Gonzaga/U ERGS. Rua Floriano Peixoto, 4557, Bairro Agrícola, 97800-000, São Luiz Gonzaga - RS. Fone: (55)3352-4370. E-mail: streckl@gmail.com

4 Pós-Graduando em Engenharia Agrícola da UFSM. Fone: (55)3220-8179. E-mail: edenirgrimm@yahoo.com.br, ivanmaldaner@yahoo.com.br
} 


\section{INTRODUÇÃO}

A cultura da batata (Solanum tuberosum L.) tem enorme significância sócioeconômica no Sul do Brasil, sendo o Estado do Rio Grande do Sul importante produtor. Esta cultura, porém, apresenta sérios problemas de cultivo devido, sobretudo, ao ataque de pragas e doenças que, sob condições ambientais favoráveis, se estabelecem rapidamente. Segundo Jones (1986) apud Martins \& Amorim (1999), a umidade é o fator ambiental que mais influencia as doenças de plantas, seguida da temperatura. Apesar da temperatura do ar ser um fator menos limitante que a umidade no desenvolvimento de doenças e pragas, a combinação temperatura-umidade condicionará o processo infeccioso de doenças ou a incidência de ataque de uma praga.

O microclima de uma cultura é influenciado por fatores como a área foliar, arquitetura e altura de plantas, os quais interferem na interceptação e no balanço de radiação, determinando diferentes regimes de temperatura e umidade do ar dentro do dossel das culturas (Monteith \& Unsworth, 1990). Em geral, a tendência diária da temperatura do ar dentro de um dossel depende do suprimento de radiação solar incidente e da camada na qual ela é interceptada, da taxa de radiação de onda longa perdida, do total de energia absorvida usada na evaporação d'água do solo e transpiração das plantas e do transporte turbulento do calor no dossel (Broadbent, 1950); além disso, a soma térmica a que ficam submetidos os diferentes extratos da parte aérea pode levar a uma aceleração maior da senescência nos níveis expostos à maior temperatura.

A modificação do ambiente em microescala pode ser fator determinante da velocidade de proliferação de pragas e doenças nos diferentes níveis do dossel de plantas, pois da interação entre hospedeiro, patógeno e ambiente tem-se, como resultado, a ocorrência ou não de pragas e doenças (Bergamin Filho \& Amorim, 1996). Essas implicações têm sido motivo de preocupação e levado à busca de práticas e estratégias para o controle eficiente, racional e economicamente viável de doenças; então sendo assim e se conhecendo as características para identificação de um genótipo cultivado e suas características fenométricas, fenológicas e de resistência a fitopatógenos específicos, pode-se avaliar, de forma mais adequada, as condições ambientais e, consequientemente, os níveis de severidade para a propagação de determinadas pragas e doenças, incluindo os efeitos relativos da estrutura do dossel de plantas no perfil de temperatura e umidade do ar. A partir dessas informações pode-se eleger o momento mais propício para as medidas de controle as quais serão realizadas somente quando as informações do sistema as definirem como necessárias.

Segundo Monteiro (2002) é oportuno aprofundar os estudos das relações entre as condições meteorológicas, principalmente do microclima da cultura e a epidemiologia da doença para, posteriormente, desenvolver métodos ou modelos que identifiquem as situações ou momentos em que a doença ocorrerá, cujo primeiro passo é monitorar corretamente as variáveis do microambiente e, se possível, estabelecer parâmetros que descrevam sua variação com o tempo ao lon- go do dia, em função das condições meteorológicas, e ao longo do ciclo, em função da mudança da dimensão e estrutura do dossel das plantas cultivadas. Descrições com esse enfoque são pouco freqüentes e raras para cultivares específicas.

A cultivar Macaca de batata é o genótipo mais cultivado na região central do Rio Grande do Sul; para ela, ainda faltam todas as informações básicas relacionadas ao crescimento e desenvolvimento das plantas e ao desenvolvimento e proliferação dos fitopatógenos Phytophthora infestans Mont de Bary e Alternaria solani, causadores da requeima e da alternaria, respectivamente, os quais ainda são dois dos principais problemas da bataticultura na região central do Rio Grande do Sul.

Com este trabalho se impôs determinar a variação vertical da temperatura do ar em um dossel de plantas de batata, cultivar Macaca, ao longo do seu ciclo de desenvolvimento.

\section{MATERIAL E MÉTODOS}

Realizaram-se dois experimentos, o primeiro em uma propriedade rural localizada no município de Silveira Martins, RS (latitude 29 $38^{\prime}$ ' S; longitude: $53^{\circ} 35^{\prime}$ W e altitude: $455 \mathrm{~m}$ ) e outro na área experimental do Departamento de Fitotecnia da Universidade Federal de Santa Maria (latitude: $29^{\circ} 43^{\prime} S$; longitude: 53 $43^{\prime} \mathrm{W}$ e altitude: $95 \mathrm{~m}$ ). O clima da região, conforme classificação de Köppen, é do tipo Cfa, subtropical úmido com verões quentes sem estação seca definida (Moreno, 1961).

O primeiro experimento foi realizado na primavera, no período de $15 / 10$ a 5/12/2003 e o segundo no outono, no período de 27/03 a 08/06/2004. Nos dois experimentos foi utilizada a cultivar Macaca. A condução da cultura foi realizada segundo as recomendações técnicas descritas em Bisognin (1996).

A temperatura do ar foi medida continuamente em uma torre, em cinco níveis $(0,15 ; 0,40 ; 1,00 ; 1,50$ e $2,20 \mathrm{~m}$ acima da superfície do solo, em 2003, a mesma foi medida a 0,$10 ; 0,40 ; 1,00 ; 1,50$ e 2,00 m, em 2004), através de termômetros de resistência elétrica de platina (Pt-100) instalados no interior de mini-abrigos; além da torre, ainda se instalaram mais três repetições com sensores Pt-100 nos níveis centro (meio) do dossel de plantas $(0,5 \mathrm{~h})$ da cultura e acima do topo das plantas, a 1,00 $\mathrm{m}$ da superfície do solo, sendo $\mathrm{h}$ a altura das plantas. Todos os sensores foram ligados a um sistema automático de aquisição de dados (datalogger), alimentado por uma bateria de $12 \mathrm{~V}$. Os sensores Pt-100 possuem uma precisão de $0,1^{\circ} \mathrm{C}$ na faixa de temperatura medida e o sistema sensor-datalogger apresenta resolução de $0,12{ }^{\circ} \mathrm{C}$ e precisão de $0,25^{\circ} \mathrm{C}$.

Os dados obtidos nas três repetições em dois níveis de medidas foram agrupados através de médias. Para a análise do microclima e dos perfis verticais do dossel da cultura da batata, utilizaram-se médias de temperatura do ar, as quais foram calculadas utilizando-se os dados no período de maior aquecimento, das 11 às $17 \mathrm{~h}$ e no período de maior resfriamento, ou seja, das 21 às $4 \mathrm{~h}$. 


\section{RESULTADOS E DISCUSSÃO}

As temperaturas médias do ar no período diurno, entre 11 e $17 \mathrm{~h}$, em um dossel de plantas de batata na primavera de 2003 e outono de 2004, foram superiores no nível mais baixo da cultura, a $0,15 \mathrm{~m}$ e/ou $0,10 \mathrm{~m}$ de altura (Figura $1 \mathrm{~A} \mathrm{e}$ 2A). No período noturno, entre 21 e $4 \mathrm{~h}$ (Figura 1B) os valores de temperatura registrados no nível a $0,15 \mathrm{~m}$ foram, na sua maioria, inferiores aos registrados a nível de $2,2 \mathrm{~m}$ de altura, mostrando predominância de inversão térmica neste período, cujo comportamento difere daquele observado no outono de 2004 (Figura 2B), em que predominou a condição de gradiente normal, isto é, a temperatura no nível de medida mais baixo do dossel $(0,10 \mathrm{~m})$ foi superior à registrada acima da cultura (2,0 $\mathrm{m}$ de altura).

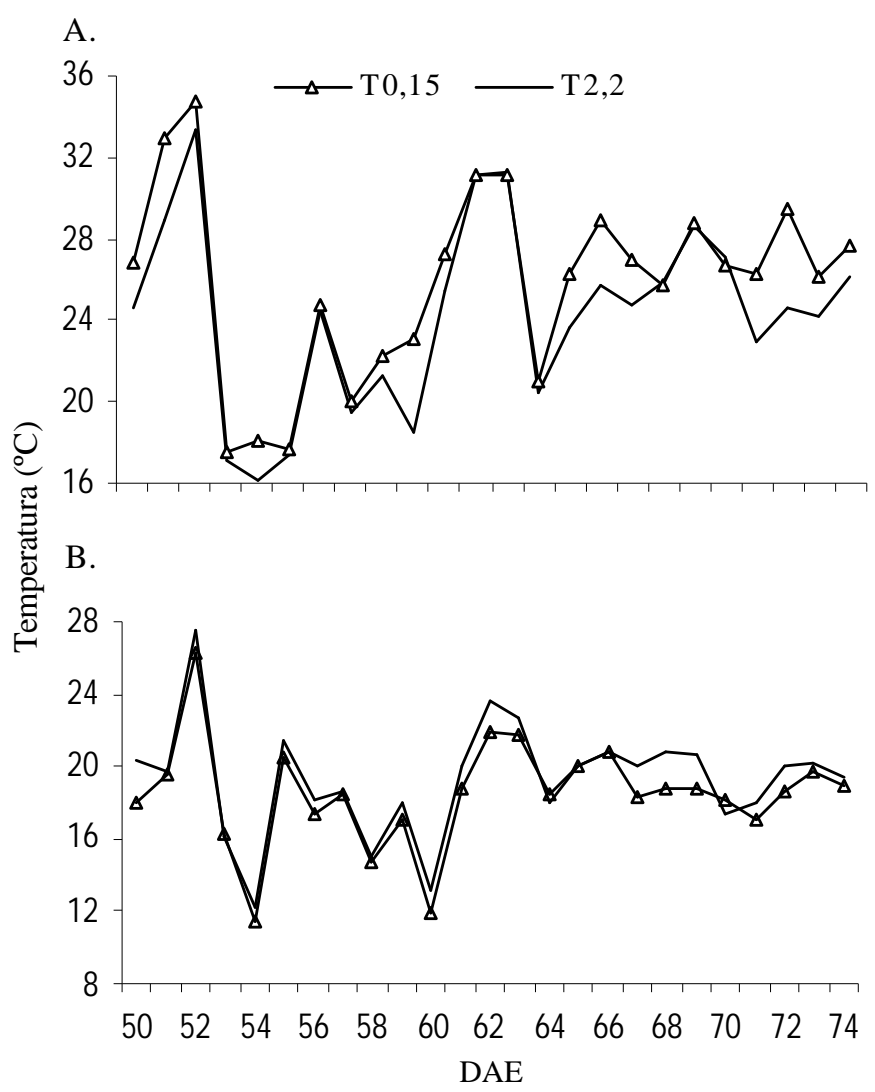

Figura 1. Temperatura média do $\operatorname{ar}\left({ }^{\circ} \mathrm{C}\right)$ no período mais quente do dia (das 11 às $17 \mathrm{~h}$ ) (A) e no período de maior resfriamento (das 21 às 4 h) (B), medida em dois níveis (0,15 e 2,2 $\mathrm{m}$ de altura), em função de dias após a emergência (DAE), em um dossel de plantas de batata

Diversas são as possíveis causas dessas diferenças entre os anos estudados. No outono de 2004 os sensores mais baixos foram instalados a $0,10 \mathrm{~m}$ e, na primavera de 2003 , a $0,15 \mathrm{~m}$. A menor distância dos miniabrigos até o solo em 2004, com superfície projetada sobre o solo de $920 \mathrm{~cm}^{2}$, provavelmente proporcionou melhor proteção da superfície do solo contra seu resfriamento por radiação de onda longa, fato confirmado em virtude de que, entre 0,4 e $0,10 \mathrm{~m}$ de altura, antes do acamamento (36 DAE), a temperatura geralmente foi mais baixa a $0,10 \mathrm{~m}$ e, após os $36 \mathrm{DAE}$, as diferenças $T_{0,40}-T_{0,10}$ bem como $T_{1,0}-T_{0,10}$, foram sempre positivas, in-

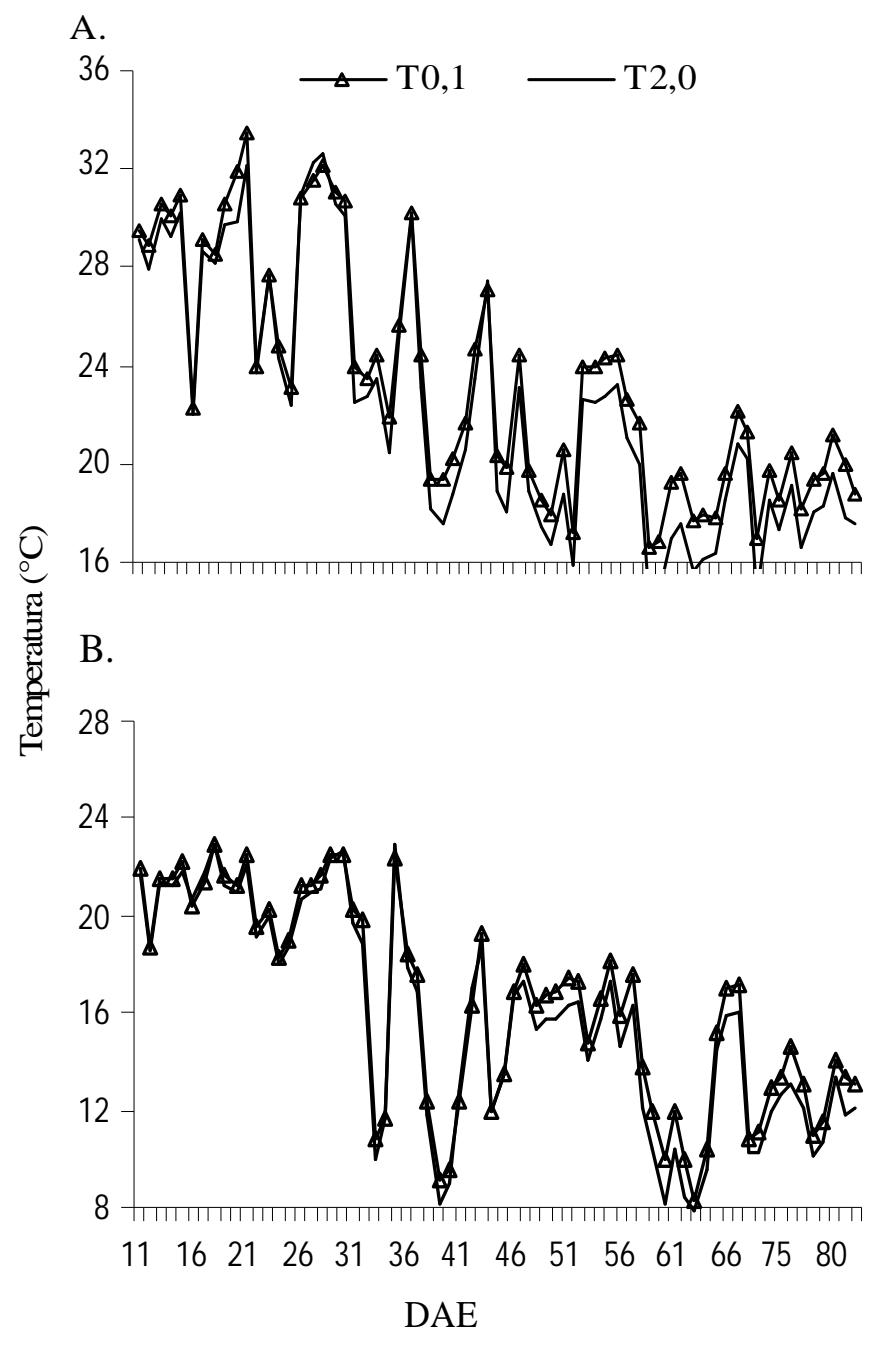

Figura 2. Temperatura média do ar no período mais quente do dia (das 11 às $17 \mathrm{~h}$ ) (A) e no período de maior resfriamento (das 21 às $04 \mathrm{~h}$ ) (B), medida em dois níveis (0,10 e 2,0 $\mathrm{m}$ de altura) em função de dias após a emergência (DAE), em um dossel de plantas de batata

dicando que também o nível de maior resfriamento foi deslocado para próximo da superfície do solo (Figura 3A e 3B); mesmo assim, as diferenças negativas $\mathrm{T}_{2,0}-\mathrm{T}_{0,10}$ continuaram e até se tornaram mais acentuadas após o acamamento, indicando que acima do topo da inversão predominava um fluxo de ar mais frio que, provavelmente, se intensificou na medida que se aproximava o final do outono.

Considerando-se a influência da topografia nos dois locais, não foi possível estabelecer uma explicação clara para este comportamento, não esperado em 2004, mas apenas se constatou que na primavera de 2003 as fileiras das plantas estavam alinhadas no sentido oblíquo às curvas de nível; esta prática, realizada pelo produtor quando foi instalado o experimento, propiciou uma condição de declive de aproximadamente 3,0 a 3,5\% ao longo de $70 \mathrm{~m}$ da pendente à montante da área de medição, facilitando a drenagem de ar frio na direção do local de medida, mantendo um fluxo contínuo de ar, o que atenuou a variabilidade espacial local e pode ter contribuído para desenvolver uma camada de inversão mais espessa em noites de ventos calmos que em 2004; ano em que o experimento foi realizado em um terreno plano cujas 


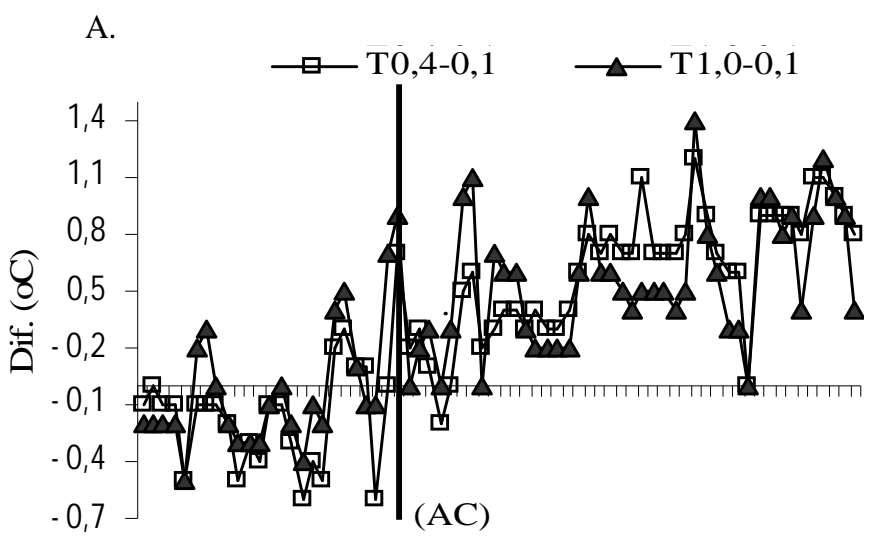

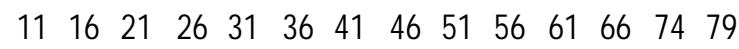

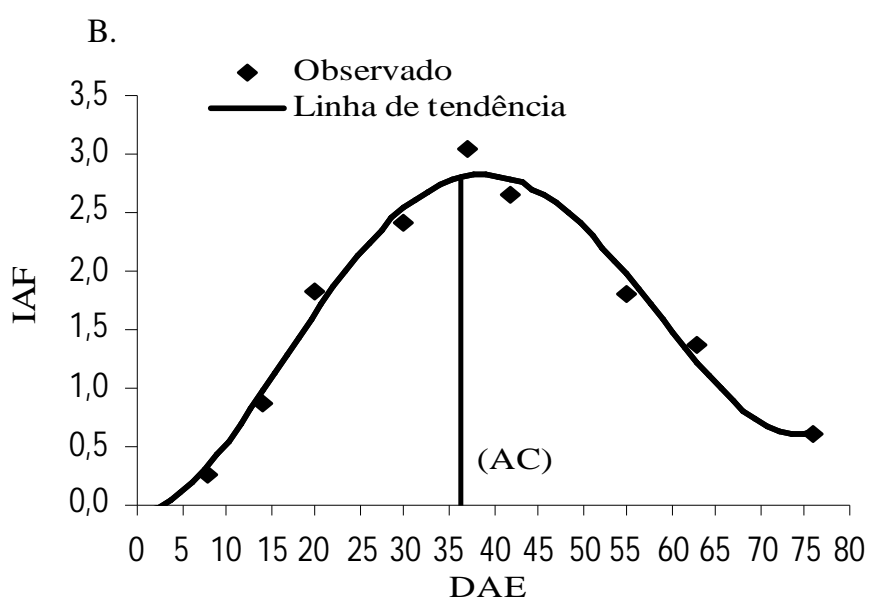

Figura 3. Diferença média de temperatura do ar (Dif.) entre os níveis de $0,4 \mathrm{e}$ $0,1 \mathrm{~m}$ de altura $\left(\mathrm{T}_{0,4-0,10}\right), 1,0$ no período de maior resfriamento, das 21 às $4 \mathrm{~h}$ (A), 0,10 m ( $\left.T_{10-1,1}\right)$ e Indice de Area Foliar (IAF) (B) em função de dias após a emergência (DAE) em um dossel de plantas de batata, CV. M acaca. A linha inteira (AC) na vertical significa o acamamento ocorrido aos $36 \mathrm{DAE}$

bordas apresentavam declividade de aproximadamente 1,0 a $1,5 \%$ para os quadrantes $\mathrm{N}$ e ESE, favorecendo a drenagem do ar frio e minimizando a inversão térmica na área do experimento. A verificação de que o topo da inversão térmica (temperatura média mais alta entre 21 e 4 h) em 2003 geralmente estava a 1,0 ou 1,5 m de altura e em 2004, se situou a 1,0 ou $0,40 \mathrm{~m}$, induz a reflexão de que esta poderia ser uma das causas. Além dessas considerações se esperava também, um pequeno efeito da maior altitude do local de realização do experimento, em Silveira Martins (455 m) em relação a Santa Maria $(95 \mathrm{~m})$ devido à menor contra-radiação da atmosfera em noites de céu límpido em áreas de maior altitude, em virtude da menor concentração de moléculas no ar, vapor d'água, dióxido de carbono e outras moléculas ou partículas absorvedoras de radiação de onda longa (Gates, 1980).

Os gradientes de temperatura média no período diurno (Figuras 1A e 2A) são maiores que aqueles do período noturno (Figuras 1B e 2B). As diferenças médias $\left(\mathrm{T}_{2,2}-\mathrm{T}_{0,15}\right)$ no período experimental na primavera de 2003, foram de $-1,72{ }^{\circ} \mathrm{C}$ no período diurno e de $+0,82^{\circ} \mathrm{C}$ no período noturno, sendo que os maiores valores observados foram de $-4,74{ }^{\circ} \mathrm{C}$ no período diurno, aos $73 \mathrm{DAE}$ (alta insolação e
$\mathrm{U}_{2}=1,2 \mathrm{~m} \mathrm{~s}^{-1}$ ) e de $+2,25^{\circ} \mathrm{C}$ no período noturno, aos $50 \mathrm{DAE}$ (sem chuva e sem vento), respectivamente (Figuras 1A e 1B).

A diferença de temperatura média entre os dois níveis extremos da torre $(2,0 \mathrm{~m}$ e $0,10 \mathrm{~m})$ de todo o período experimental de 2004, no período mais quente do dia (das 11 às $17 \mathrm{~h}$ ), foi de $-1,12^{\circ} \mathrm{C}$ (Figura $2 \mathrm{~A}$ ) e de $-0,62^{\circ} \mathrm{C}$ para o período noturno (Figura 2B). As diferenças foram menores no início do cultivo, aumentando no decorrer do ciclo devido à estabilidade térmica mais freqüente na medida em que se aproxima o final do outono. A maior diferença entre os níveis 2,0 e $0,10 \mathrm{~m}$ foi de $-1,84^{\circ} \mathrm{C}$ aos $60 \mathrm{DAE}$, período noturno em que ocorreu céu límpido e $\mathrm{U}_{2}<0,2 \mathrm{~m} \mathrm{~s}^{-1}$; porém, desde 0,1 até $1,0 \mathrm{~m}$ de altura se deu inversão térmica. Entre os demais níveis também se observou um gradiente maior da temperatura no período diurno e um menos acentuado à noite. À noite, no entanto, a inversão foi, em geral, pouco intensa e/ou de pequena abrangência vertical alcançando, comumente, apenas 1,0 $\mathrm{m}$ de altura, tendendo a confirmar a idéia de que a inversão térmica nos dois locais de experimento apresentou abrangência vertical pequena, bem abaixo de 2,0 m de altura, sobretudo em Santa Maria mas ainda assim acima do topo do dossel. Em geral, esses resultados estão de acordo com Rosenberg (1974), que demonstra, que durante o aquecimento de um dossel de plantas de soja os gradientes são normais e acentuados e no período de resfriamento ocorrem gradientes menos acentuados que nas horas mais quentes; é portanto, normal ocorrer pequena inversão térmica.

Observa-se, analisando as diferenças de temperatura aos 50 DAE, na primavera de 2003 (Figura 4A) e aos 53 DAE, no outono de 2004 (Figura 4B), em que a velocidade do vento foi baixa e houve boa disponibilidade de radiação solar, que as diferenças entre os dois níveis analisados são acentuadas nos dois experimentos; esses resultados seguem, portanto, a tendência teórica de que os gradientes verticais de temperatura são atenuados devido ao incremento do transporte vertical e horizontal das moléculas constituintes do ar causado pelo vento (Monteith \& Unsworth, 1990) (Figura 4) e, por outro lado, são intensificados pelo aumento da dimensão positiva durante o dia, ou negativa, à noite, do saldo de radiação (Heldwein, 1993).

Verificou-se, nas Figuras 5A e B, que não ocorreram grandes diferenças entre as temperaturas medidas nos dois níveis, aos 52 e 36 DAE; conclui-se, então, que nesses dois dias os gradientes verticais foram atenuados, em razão, sem dúvida, da velocidade do vento mais elevada. Ventos fortes a moderados, associados a um alto grau de nebulosidade (com ou sem precipitação) são condições que geralmente fazem o gradiente vertical de temperatura, junto à superfície tender a zero (Panofsky, 1977; Monteith \& Unsworth, 1990; Heldwein, 1993).

Os perfis de temperatura do ar representados na Figura 6A e B, obtidos aos 53 DAE e 57 DAE, em 2003, são típicos de medidas realizadas durante a ocorrência de precipitação sob velocidade do vento moderada a alta, durante todo o período diurno. Verifica-se que a temperatura do ar apresentou pequena variação vertical nessas condições, em virtude da concentração de vapor d'água no ar ter sido homogeneizada pelo vento, pela chuva e também pequena magnitude 
A.

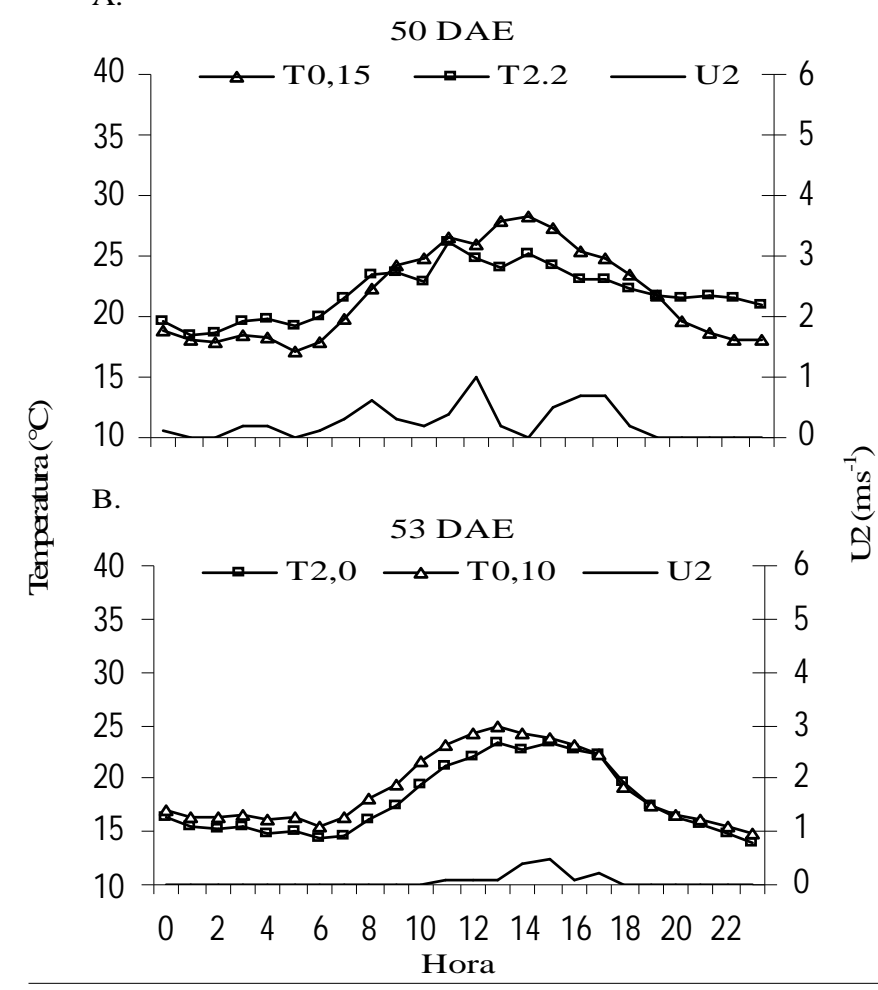

Figura 4. Temperatura média do $\operatorname{ar}\left({ }^{\circ} \mathrm{C}\right)$ a $2,2 \mathrm{~m}\left(\mathrm{~T}_{2,2}\right)$ e a $0,15 \mathrm{~m}\left(\mathrm{~T}_{0,15}\right)$ de altura, na primavera de 2003 (A) e a $2,0 \mathrm{~m}\left(\mathrm{~T}_{2,0}\right)$ e a $0,10 \mathrm{~m}\left(\mathrm{~T}_{0,10}\right)$ de altura, no outono de 2004 (B) e velocidade do vento a $2,0 \mathrm{~m}$ de altura $\left(\mathrm{U}_{2} \mathrm{~m} \mathrm{~s}^{-1}\right)$, em um dossel de plantas de cultura da batata, cultivar Macaca, aos 50 e 53 dias após emergência (DAE)

A.

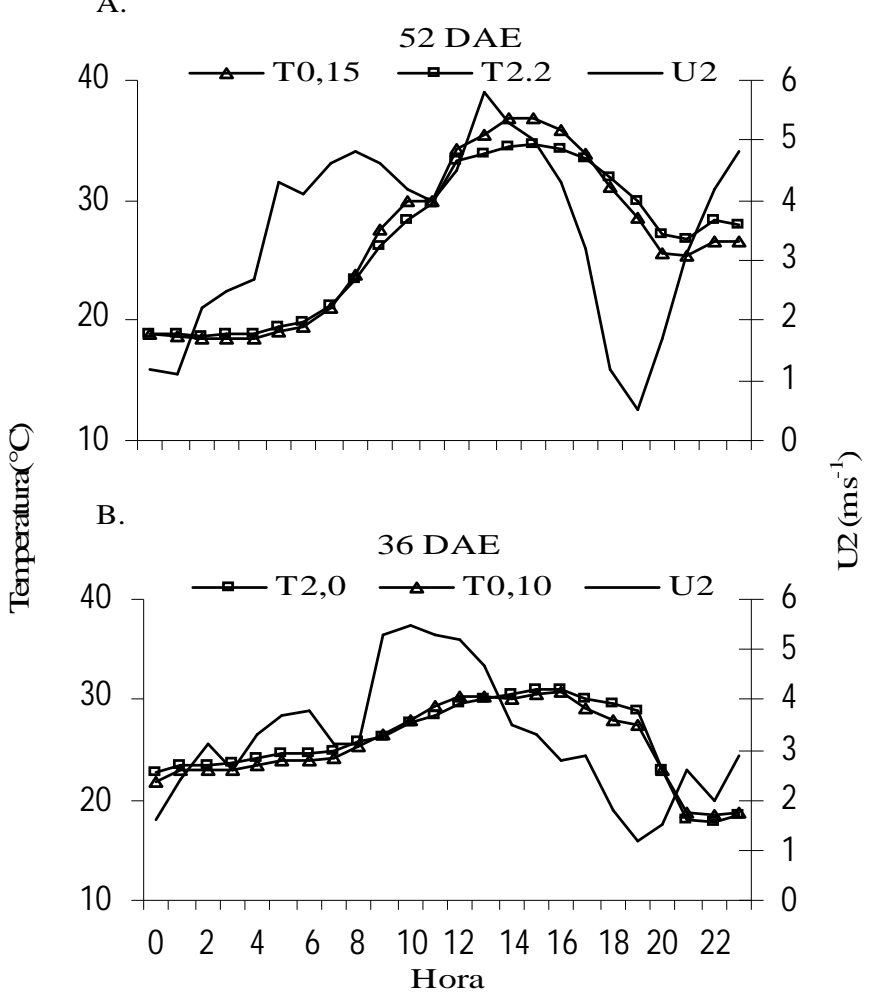

Figura 5. Temperatura média do $\operatorname{ar}\left({ }^{\circ} \mathrm{C}\right)$ a $2,2 \mathrm{~m}\left(\mathrm{~T}_{2,2}\right)$ e a $0,15 \mathrm{~m}\left(\mathrm{~T}_{0,15}\right)$ de altura, na primavera de 2003 (A) e a $2,0 \mathrm{~m}\left(\mathrm{~T}_{2,0}\right)$ e a $0,10 \mathrm{~m}\left(\mathrm{~T}_{0,10}\right)$ de altura, no outono de 2004 (B) e velocidade do vento a $2,0 \mathrm{~m}$ de altura $\left(\mathrm{U}_{2} \mathrm{~m} \mathrm{~s}^{-1}\right)$, em um dossel de plantas de cultura da batata, cultivar Macaca, aos 52 e 36 dias após emergência (DAE)
50 DAE

$\diamond$ Tdia $\square \mathrm{Tn}$

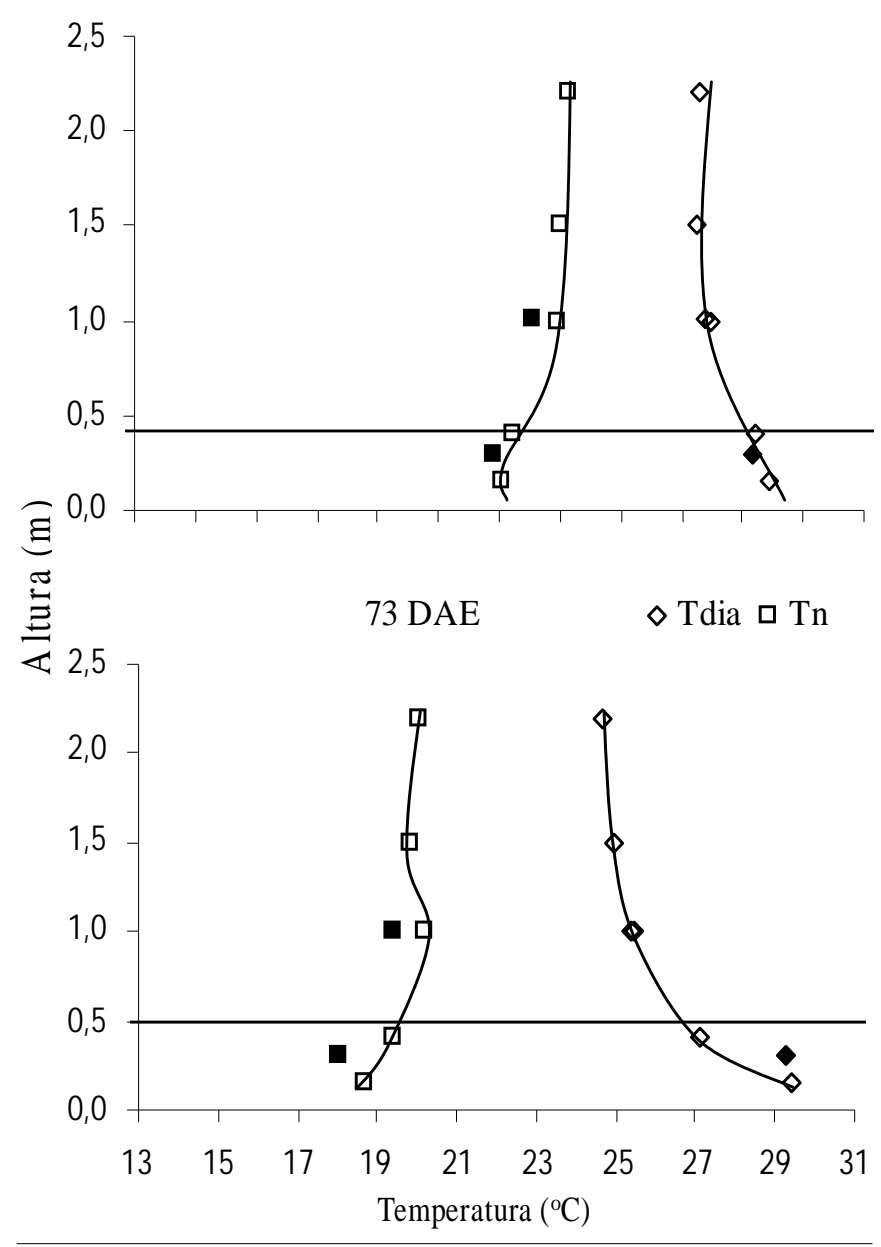

Figura 6. Perfil vertical da temperatura do ar (T) em um cultivo de batata, cV. Macaca, aos 53 e 57 dias após a emergência, nos períodos das 11 às $17 \mathrm{~h}$ (Tdia) e das 21 às $4 \mathrm{~h}(\mathrm{Tn})$ medida em dois níveis com três repetições $(\mathbb{\mathrm { e }})$ e na torre com cinco níveis $(\square \mathrm{e} \diamond)$, em dias com ocorrência de precipitação pluvial. A linha traçada na horizontal representa a altura média do dossel.

do saldo de radiação e, ainda, pela taxa de evaporação que, desta forma, minimizou as trocas de energia do ar com a superfície o que, sob um processo de mistura forçada do ar pela ação do vento, não permitiu que se desenvolvessem gradientes verticais de temperatura do ar dentro e acima do dossel das plantas de batata. Como no período noturno (n) o céu permaneceu encoberto e o vento continuou com velocidade acima de 1,0 $\mathrm{m} \mathrm{s}^{-1}$, limite de velocidade a $2,0 \mathrm{~m}$ de altura, que geralmente é suficiente para produzir fluxo de ar turbulento entre as plantas de batata (Heldwein, 1993), os perfis verticais de temperatura pouco se alteraram, tanto em valor quanto em gradiente, em relação ao período diurno, exceto aos $57 \mathrm{DAE}$, em que ocorreu pequena inversão térmica próxima ao topo do dossel de plantas.

Aos 50 e 73 DAE (Figura 7A e B), em que não ocorreu precipitação, a temperatura do ar no período diurno decresceu com a altura. Verifica-se que a variação vertical da temperatura do ar no período diurno aos 50 DAE foi menor que aos 73 DAE devido, provavelmente, à ocorrência de nebulosidade parcial nesse dia; deu-se inversão térmica nos dois dias em virtude da ocorrência de noites calmas e límpidas. 


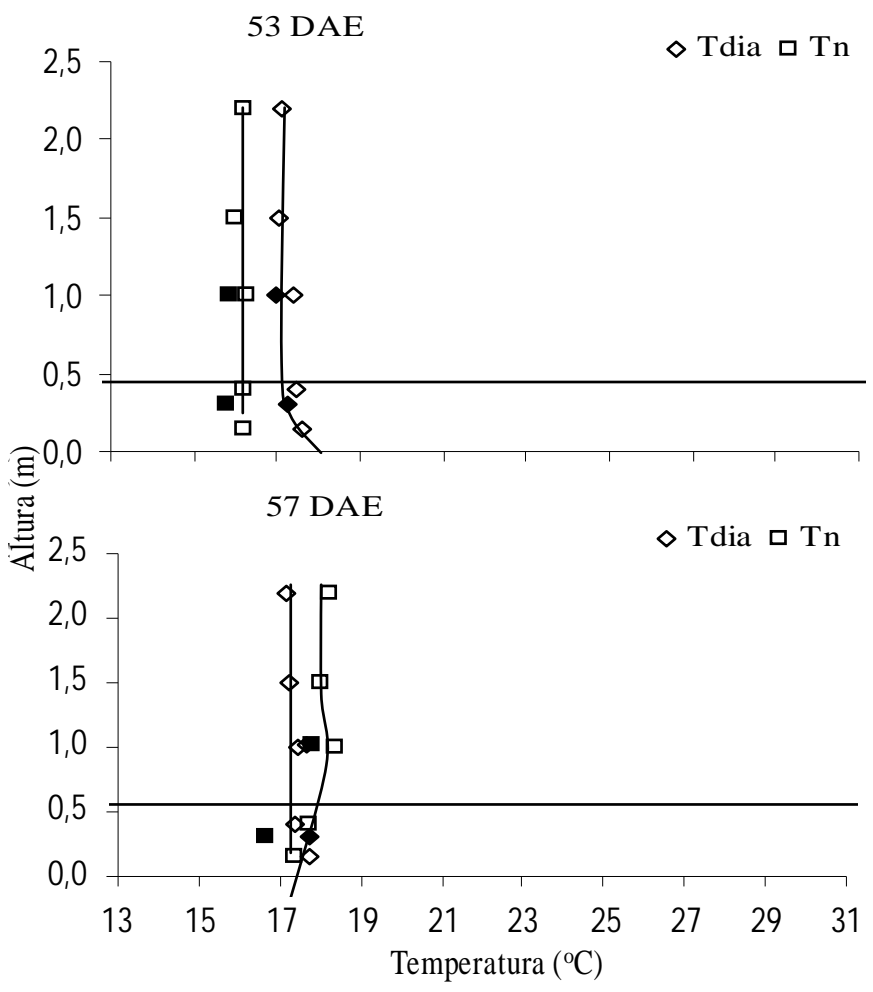

Figura 7. Perfil vertical da temperatura do ar (T) em um cultivo de batata, $\mathrm{cv}$. Macaca, aos 50 e 73 dias após a emergência (DAE), nos períodos das 11 às $17 \mathrm{~h}$ (Tdia) e das $21 \mathrm{~h}$ às $4 \mathrm{~h}$ (Tn) medida em dois níveis com três repetições ( $\mathrm{C}$ e), e na torre com cinco níveis $(\square \mathrm{e} \diamond)$, em dias em que não ocorreu precipitação pluvial.

O bs.: A linha traçada na horizontal representa a altura média do dossel

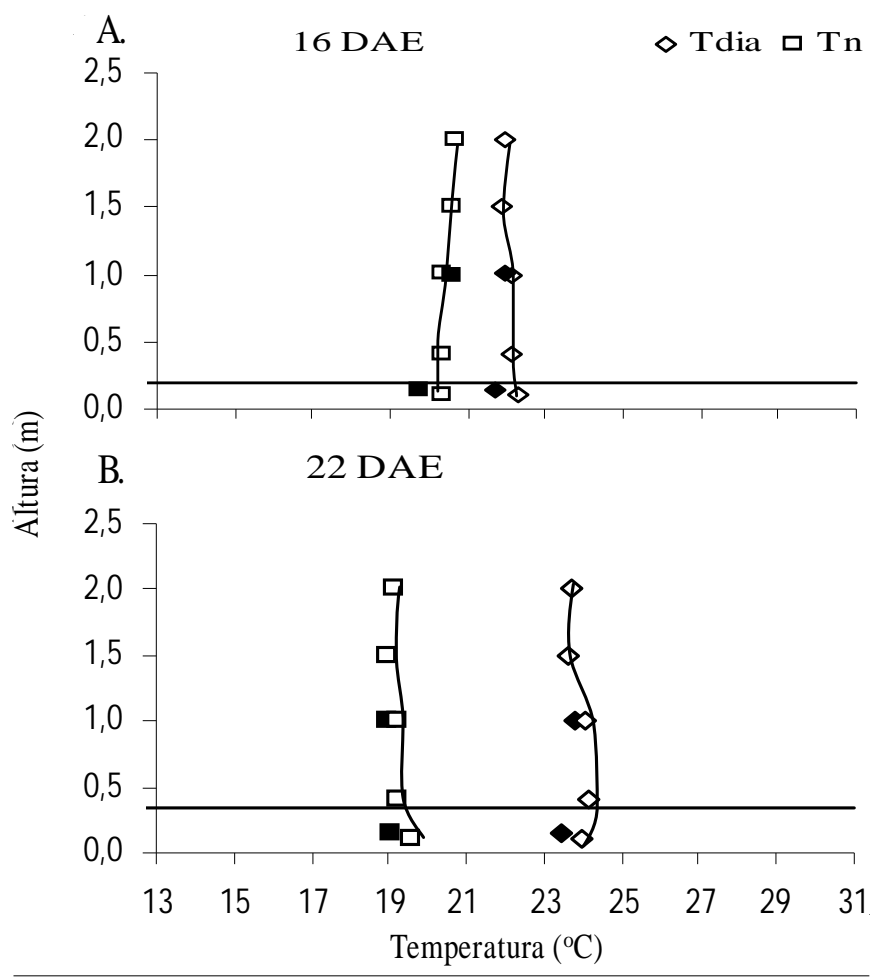

Figura 8. Perfil vertical da temperatura do ar (T) em um cultivo de batata, $\mathrm{Cv}$. Macaca, aos 16 e 22 dias após a emergência (DAE), nos períodos das 11 às $17 \mathrm{~h}$ (Tdia) e das 21 às $4 \mathrm{~h}$ (Tn) medida em dois níveis com três repetições ( $\mathbf{l}$ e e na torre com cinco níveis $(\square e \diamond)$, em dias em que ocorreu precipitação pluvial. O bs.: A linha traçada na horizontal representa a altura média do dossel
Aos 16 e 22 DAE de 2004, a temperatura do ar foi praticamente constante durante todo o período diurno, em razão da ocorrência de precipitação durante parte do período e de nebulosidade no restante do dia, não permitindo o aquecimento do dossel (Figura 8A e B). No período noturno, em razão, talvez, da continuidade da nebulosidade e alta umidade do ar, a temperatura do ar foi praticamente constante apresentando pequena variação com a altura.

Aos 19 e 24 DAE, no outono de 2004 (Figura 9A e B) no período mais quente (das 11 às $17 \mathrm{~h}$ ) a temperatura do ar sempre apresentou maior valor no topo do dossel $(0,40 \mathrm{~m})$. Acima do dossel ocorreu decréscimo com o aumento da altura; esses dois dias apresentaram, como característica, céu límpido e baixa velocidade do vento. No período noturno a temperatura do ar foi praticamente constante não apresentando inversão térmica; tal comportamento se deve, provavelmente, ao fato de que no período noturno, ocorreu aos $19 \mathrm{DAE}$, velocidade do vento mais elevada e, aos $24 \mathrm{DAE}$, céu parcialmente nublado.

A análise dos perfis de temperatura do ar nas diferentes condições meteorológicas, permite deduzir algumas regras gerais sobre a variação desse elemento com a altura, em um cultivo de batata, as quais poderão ser úteis quando se dispõe apenas de dados de estações meteorológicas instaladas nas condições padrão (sobre área relvada).

Nas noites com chuva ou com nevoeiro ou, ainda, nas noites de céu nublado e com vento, desde que este não seja seco e quente, os perfis de temperatura do ar não apresen-

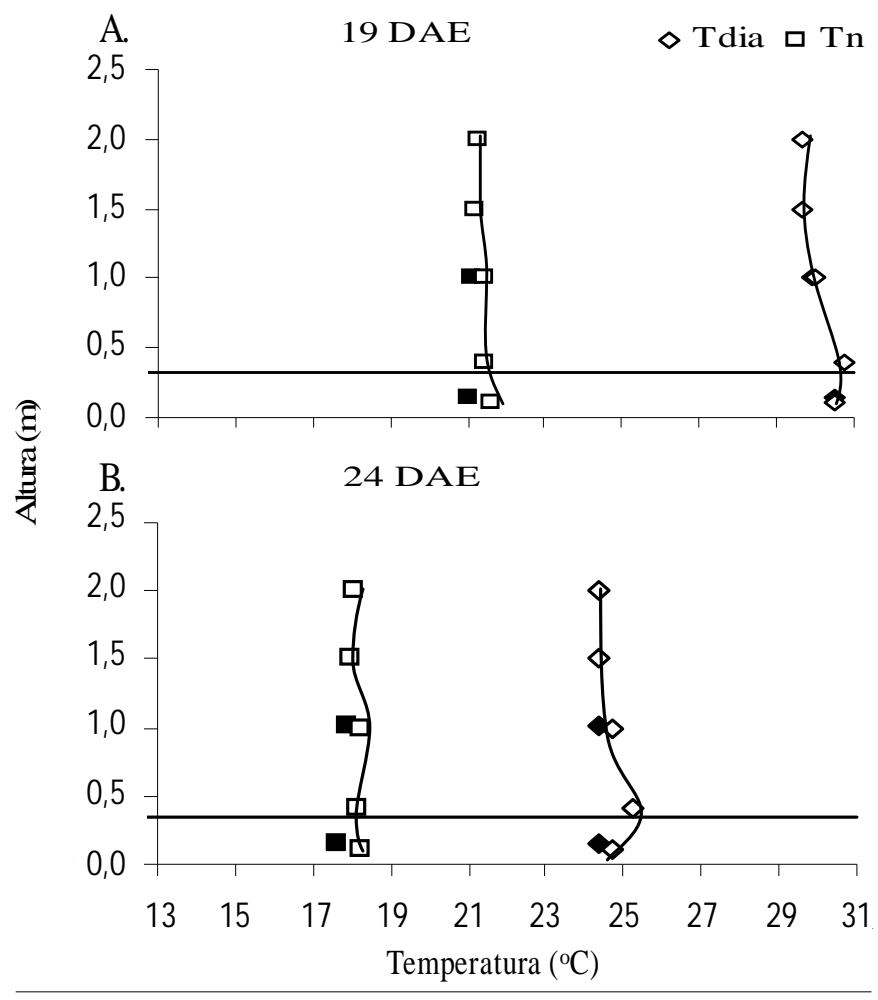

Figura 9. Perfil vertical da temperatura do ar (T) em um cultivo de batata, cv. M acaca, aos 19 e 24 dias após a emergência (DAE), nos períodos das 11 às $17 \mathrm{~h}$ (Tdia) e das 21 às $4 \mathrm{~h}(\mathrm{Tn})$ medida em dois níveis com três repetições ( $\mathrm{e}$ ), e na torre com cinco níveis $(\square \mathrm{e} \diamond)$, em dias em que não ocorreu precipitação pluvial. O bs.: A linha traçada na horizontal representa a altura média do dossel 
tam gradientes acentuados. Pode-se, então, inferir que nessas respectivas condições a temperatura do ar em um dossel de plantas de batata pode ser similar no mesmo horário, aos valores de temperatura do ar medidos no abrigo meteorológico das estações instaladas na condição padrão.

\section{CONCLUSÕES}

1. Os valores médios dos gradientes de temperatura entre 2,2 e $0,15 \mathrm{~m}$ de altura $\left(\mathrm{T}_{2,2}-\mathrm{T}_{0,15}\right)$ são positivos no período diurno (das 11 às $17 \mathrm{~h}$ ) enquanto no período noturno (das 21 às $4 \mathrm{~h}$ ) não apresentam variação definida.

2. A temperatura média diurna foi maior nos níveis inferiores do dossel, sendo os gradientes de temperatura do ar mais acentuados no período diurno que no período noturno.

3. O acamamento das plantas influi no perfil da temperatura do ar, deslocando o nível de troca energética em direção à superfície do solo.

4. A inversão térmica vertical média no período noturno é pouco acentuada, abaixo de 2,0 $\mathrm{m}$ de altura, sendo maior em noites límpidas e calmas.

5. Os gradientes mais acentuados de temperatura ocorrem em dias calmos e límpidos ou com pouca nebulosidade; em dias com precipitação ou com nevoeiro ou ainda, em noites de céu nublado e com vento, desde que este não seja seco e quente, a temperatura do ar apresenta pouca variação horizontal e vertical.

\section{AGRADECIMENTOS}

Os autores agradecem ao Conselho Nacional de Desenvolvimento Científico e Tecnológico (CNPq), à Fundação Coordenação de Aperfeiçoamento de Pessoal de Nível Superior (CAPES) e à Fundação de Amparo à Pesquisa do Estado do
Rio Grande do Sul (FAPERGS), pelas respectivas bolsas recebidas e à FAPERGS pelo financiamento parcial da pesquisa.

\section{LITERATURA CITADA}

Bergamin Filho, A.; Amorim, L. Moléstias de plantas tropicais: epidemiologia e controle econômico. São Paulo: Ceres, 1996. 289p.

Bisognin, D. A. Recomendações técnicas para o cultivo da batata no Rio Grande do Sul e Santa Catarina. Santa Maria: UFSM. 1996. 64p. Boletim Técnico.

Broadbent, L. The microclimate of the potato crop. Quartely Journal of the Royal Meteorological Society, v.76, n.330, p.439-454. 1950.

Gates, D. M. Ecologycal biophysics. Springer: New York, 1980.611p.

Heldwein, A. B. Ermittlung der Taubenetzung von Pflanzenbeständen durch Anvendung mikrometeorologischer Verfahren sowie mittels konventioneller Methoden. Berlin: TU-Berlin, 1993. 206p. Tese Doutorado

Martins, M. C:, Amorim, L. Efeito do período de molhamento foliar em componentes monocíclicos da ferrugem do pessegueiro. Revista Fitopatologia Brasileira, v.24, n.4, p.552-555, 1999.

Monteiro, J. E. B. A. Microclima e ocorrência de ramulose no algodoeiro em diferentes densidades populacionais. Piracicaba: ESALQ/USP, 2002. 99p. Dissertação Mestrado

Monteith, J. L.; Unsworth, M. H. Principles of environmental physics. 2 ed. New York: Edward Arnold, 1990. 291p.

Moreno, J. A. Clima do Rio Grande do Sul. Porto Alegre: Secretaria da Agricultura, 1961. 46p.

Panofsky, H. A. Wind structure in strong winds below $150 \mathrm{~m}$. Wind Engineering, v.1, p.91-103, 1977.

Rosenberg, J. N. Microclimate: The biological environment. New York: Wiley \& Sons, 1974. 315p. 